\title{
Per Pinstrup-Andersen, Peter Sandøe (eds), Ethics, Hunger and Globalization. In Search of Appropriate Policies. Springer, 2007
}

\author{
Cor van der Weele
}

Accepted: 6 February 2009/Published online: 20 February 2009

(C) The Author(s) 2009. This article is published with open access at Springerlink.com

\begin{abstract}
"The statistics are well known." After this first sentence of the book, and some examples of the statistics, an equally well known question follows: "Why does so much human misery exist in a world that possesses enough resources to assure a healthy and comfortable life for all world citizens?" The next question takes us to ethics: "Is it fair?" The rhetoric coming from policy makers is clear enough, the authors note: it is unfair and something must be done. But the rhetoric is followed by insufficient action. The question then becomes how ethics may help to close this gap: "We hope that the book will help develop a shared vision that combines ethics and economics."
\end{abstract}

How ethics may help in the struggle against poverty and hunger is the main search of this book. During this search, the collection is looking for appropriate policies, as the subtitle says, thus making us look forward to specific ways to proceed. A distinguished collection of authors from different backgrounds approaches the problem from the perspective of ethics, religion, international law, economics, and the world of NGOs, while in the second half the book zooms in on policies of food and agriculture: GM crops, agricultural subsidies and tariff walls, and food safety standards.

It is a wonderful development that ethics is turning global, gives priority to the most urgent global problems, and wonders how it can help. The search is not an easy one, as this book richly illustrates.

The statistics may be well known, they are nevertheless present throughout the book: many chapters give data and comparisons from which moral perplexity follows almost automatically. "Absolute poverty is estimated to affect about 1.2 billion people." " $46 \%$ of the world's population lives below the US\$ 2 a day poverty line." "At least 140 million children in the developing world are seriously undernourished." "In 2003, 625 people were killed in terrorist attacks, while some 10 million died of starvation."

A lively way to imagine inequality statistics is through the "Parade of Dwarfs (and a few Giants)", a graphic metaphor devised by the Dutch economist Jan Pen in the early 1970s. In this image, people's height is proportional to their income. All people are lined up in order of height, and everyone marches by in a 1-h parade, the smallest at the front.

C. van der Weele $(\bowtie)$

Wageningen University, Wageningen, The Netherlands

e-mail: Cor.vanderweele@wur.nl 
Pen's parade, which covered only the UK, starts underground (the marchers suffer losses) and continues for 20 min with marchers who are so small as to be invisible. After half an hour dwarfs are marching by in seemingly endless numbers. Only at $12 \mathrm{~min}$ before the end we see people of average height. In the last few minutes, giants loom up (that's us, more or less), while in the very last seconds, a few participants rise up for miles. Richard Gilbert opens his chapter (on globalization and religions) with this parade, and continues with global data of today: "The richest $1 \%$ of people in the world receives as much as the bottom 57\%." And "to add to the perplexity": most of the growth of the world population will be in the poorest countries.

The moral perplexity and feelings of urgency and frustration are voiced in many ways, like the statistics, and here, too, we get global comparison: "We know that half the world's population are living on one or two dollars a day, while the middle classes of affluent nations enjoy standards of living that feature-and increasingly revolve around-orgiastic hedonism and consumerism." (Lou Marinoff, p. 29) In response to this situation, a firm moral answer has long been with us, again in a paper stemming from the early 1970's, Peter Singer's "Famine, Affluence and Morality." Its central principle is cited in several chapters: "If it is in our power to prevent something very bad from happening, without thereby sacrificing anything of comparable moral significance, we ought to do it."

Pinstrup-Andersen himself is one of the authors who cite Singer's principle, along with the fact that the rule is clearly not followed even remotely. For the failure to apply the principle, there are several possible explanations, Pinstrup-Andersen suggests; the "obvious one" being that people who are far away from us are less significant. But he does not pursue such explanations (something I will return to). Morally, there is no excuse for inaction, and frustration and cynicism about the "rhetoric-action" gap color the chapter. "The lack of action is accompanied by much rhetoric, plans, targets and promises. The most cynical of these promises and agreements is undoubtedly the United Nations' Declaration that freedom from hunger is a basic human right. It is cynical because it is not empowered with any means to enforce it."

For a way out, Pinstrup-Andersen relies on self-interest, since in the globalized world problems of the poor very soon become our own problems, through lack of markets, terrorism, illegal immigration, contagious diseases, etc. Yet even this way out is not working as it should, and again several possible explanations are offered briefly: lack of shared vision, short time horizons, incident-driven media attention, lack of understanding of economics.

Lou Marinoff, in the next chapter, describes humans as thoroughly self-regarding, short sighted and rapacious predators (rather out of tune with the present popularity of Frans de Waal's message that empathy and cooperation are just as ingrained in human nature). Morality, writes Marinoff, arises mainly in favorable, village-like circumstances in which humans are knitted together by a spirit of community. Such circumstances are not characteristic for our world, where community is superseded by technology. Marinoff discusses the usual ethical theories, though he does not really appear to believe in their power. While the most recent branch of moral discourse, which centers on human rights, may represent some of humanity's best hopes, he says, it also highlights our worst despair. For example, despite whatever right to equality, humans are born extremely unequal. The burning question is not the precise ins and outs of some hypothetical equality, but whether humanity finds ways to overcome the extreme and debilitating inequalities in the world. Given the present state of the world, the human population curve, depleted natural resources, and on and on, the 21 st century is likely to witness unimaginable horrors. 
So far, ethics does not seem to offer much: Pinstrup-Andersen thinks we should rely on self-interest, though that hardly seems to help either. Marinoff is even more pessimistic. Yet, he is right that human rights are now at the center of human hopes. The author who is cited even more often than Peter Singer is Amartya Sen, who in 1981, in his Poverty and Famine, wrote that the emphasis should not be on food availability (there is enough food) but on people's entitlements, to food and other goods. Such entitlement implies the capability of people to purchase food, and this requires democracy, Sen argued. This approach has now widely been assimilated in a human rights approach to development that has replaced (pure) utilitarianism: we should not just look at the outcomes; the means also count heavily. The enthusiasm about a human rights approach is reflected in Mary Robinson's foreword, where she points out that through human rights we can not only open up new avenues but also draw on legal tools. The big challenge is now to make these legal tools effective. Clearly, rights can be effective only when they correlate with duties that can be enforced. Asbjørn Eide's chapter on the human rights approach illustrates that this amounts to a long and arduous struggle. He describes various milestones in the international recognition of the right to adequate food. But while "an impressive set of legal standards" is now available, the main problem is that it is mainly "soft law," which is to say that there are no enforcement mechanisms.

In the next chapter, Urban Jonsson invites us to appreciate the UN system of human rights as one of the most positive manifestations of globalization. He translates the "rhetoric-action" gap into a gap between theory and practice and proposes that it can be closed through human rights, which provide Sen's entitlements with the correlative duties and yield a view in which human rights and democracy are intimately connected and interdependent. Jonsson argues that from a human rights perspective, the Millennium Development Goals are still too outcome-oriented. With such conventional goal-oriented development efforts, the rhetoric-action gap will not disappear, he thinks; a rights based approach will be needed. But while Jonsson makes it very clear that human rights point in wonderful directions, as a "theory," he does not clearly point out how, in practice, they are superior in closing the theory-practice gap.

Yet there are success stories in the world; there are countries where sustained effort has led to reduction, in some cases spectacular reduction, of hunger and poverty. Sartaj Aziz looks at lessons that can be learned from seven countries: China, Korea, Vietnam, Malaysia, Chile, Uganda, and Tunesia. All these countries had an average rate of economic growth of at least $3 \%$ in the 1990s. But economic growth alone is not enough. The contribution of this growth to poverty reduction is greater in countries that care for the productivity and trade conditions of their farmers. Further, the countries achieved macroeconomic stability through fiscal discipline, and they invested in education, health, and infrastructure. They had strong leadership that succeeded in reducing violence. They had programs and policies to target less-developed regions and groups, and policies for reducing income disparities. Last but not least, they had strategies for the decentralization of responsibilities to local levels. Such strategies worked better when poor people were mobilized into community organizations. Empowerment and rights are again important, but the chapter also pictures how successful policies are enormously diverse and practical, and sometimes squarely outcome-oriented rather than human rights based. After all, the most impressive reduction of hunger is taking place in China. Human rights protagonists do not always seem to acknowledge this.

It is impossible, in a review, to do justice to all the contributions in a book like this, where there are so many different approaches. There are two chapters on religious attitudes to poverty and hunger, which both note that religions, while zooming in on individual 
attitudes, tend to neglect power structures. There is a chapter about hunger from an NGO perspective that affirms the rights-based approach. A chapter on equality as a controversial ideal in economic contexts pictures the extreme inequalities in the world. This brings to mind Marinoff's sigh that in a world where the least off are not living a little less comfortably, but die, the burning question is not hypothetical equality but how the worst inequalities can be remedied. Also, there are two chapters on GM food, both expressing great frustration with the GM debate and its huge amounts of repetition and polarization. Both chapters take detailed looks at the claim that GM is needed to solve world hunger and that this overrides other ethical concerns. One chapter (by Peter Sandøe and Kathrine Madsen) concludes that there are a lot of other and much more obvious ways in which hunger and suffering can be prevented, and that it may be time to change the focus to these other ways. The second chapter (by Paul Thompson) concludes that GM is a valid tool for addressing world hunger, but that its proponents have poisoned the debate by not treating the opponents respectfully.

The chapters illustrate the widespread fatigue with GM debates. But the hopeful shift in the debate that can be witnessed these years, from GM itself to the wider issues of corporate power and intellectual property, is absent from the book.

The chapter on "the ethics and economics of changing behavior" looks at institutional incentives for change, and considers how food ethics could be strengthened. It wonders, for instance, whether the medical institutionalizing of ethics (with its oaths and codes and committees) could be transplanted to the domain of food. Codes of food ethics have only been very modestly successful so far, but the introduction of a "Hippocratic oath" for food actors should be considered, the authors think. Yet they also note that "getting more ethical" in the food domain will not necessarily lead to the end of hunger. Ethics may just as well focus on other and more marginal improvements.

This latter concern is the central worry of the chapter on food safety standards. Food safety is a valid concern, of course, but the raising of standards is heavily dominated by the rich countries and tends to escalate, largely without taking the effects for poor countries into account. Aflatoxin is a well known and relatively well researched example, where presumably marginal health gain in Europe led to great (it is disputed how great) loss of export revenues in Africa. It is one of the rare cases where attempts have at least been made to evaluate the distribution of costs and benefits. Such evaluations are a necessary step on the way to a more inclusive moral approach to food safety.

In the course of the book, many policies are recommended in the struggle against poverty and hunger, varying from investments in education and healthcare to the replacement of meat eating with vegetarianism. Often, doing good is primarily a matter of dismantling the bad, and one set of notoriously bad institutions is mentioned again and again and again throughout the chapters: agricultural subsidies and tariff walls. They greatly add to global poverty, they are greatly unjust and they should urgently be reformed, everybody agrees. Two chapters deal with the question: how? One (by Tutweiler and Straub) takes it that open trade is the key determinant of economic growth, and that economic growth is the only path to the end of poverty. It puts its hopes on removing tradedistorting policies of rich and poor countries alike, with flanking measures to prevent short term disadvantages for poor countries. The other chapter (by Devinder Sharma), which describes how the rich countries are misusing open trade agreements for their own benefit, argues that the only morally acceptable way forward is to acknowledge the need for national food sovereignty and the right of every country to protect its own agriculture. Further, developing countries should be allowed to restore restrictions and tariffs, and the human right to food should be the basis of a specific multilateral effort against hunger. 
These chapters illustrate the complexity of policy issues. About the harmfulness of OECD agricultural policy, authors could not agree more. Yet, when it comes to solutions, no crystal clear picture emerges. It is not easy to get a grip on the issues and on top of that, the world is changing all the time. Since the book was written, a big food crisis as well as a big credit crisis struck. The crises have increased the amount of hungry people in the world. They have strengthened many countries' fears about being dependent on other countries. Mistrust of complete liberalization has only increased, and finding a balance between justifiable protection and distorting tariffs and dumping is more urgent but perhaps more difficult than ever. Meanwhile, as usual, billions of euros that had been promised by the rich countries in response to the food crisis have not been forthcoming.

In the final chapter, the editors return to the main question of the book: how ethics may help in these struggles. Noting that theoretical ethics is a field of deep disagreement, the role they see for academic debate is mainly one of clarification and the unearthing of assumptions. For example, the difference between utilitarian and deontological lines of reasoning still is worth pointing out in many contexts. The book has been fulfilling this task: several chapters contain a presentation of the different traditions in ethics, and how they are present in development contexts. The clearest illustration is perhaps that the dominant utilitarian approach has been "added on," as the authors say, by Sen's theory of entitlements, or capabilities. They could as well have said that Sen's theory provided a bridge to the eternal rival, deontology, with human rights now increasingly at the center of attention in contexts of development. Through international law, rights have become the focal point of a system of global consensus. International law is still a long way from being enforceable, and may still be dominated by powerful countries, in short, it is far from perfect. But there is no alternative, say the editors, since "it is necessary to operate with a shared ethical vision and binding minimum of ethical standards" (p. 317). What we see is that, in the movement to consensus, ethics becomes law. But enforceability of international law is still a major challenge. And here, the authors say, picking up their earlier theme, the problem is not lack of agreement, but lack of motivation.

Lack of motivation makes for the gap between "rhetoric" and action that they noted at the beginning of the book and with which they now close it. They propose that ethics may play a role here by providing "coordination of action." For example, ethics can bring out the ethical assumptions in policy options, thus helping to integrate ethical consideration into economic and political deliberation. Also, it should be analyzed why words are not followed by action, with the central goal of promoting new action. They are skeptical of the institutionalization of ethics (through oaths and codes etcetera), instead they put their hope on open and respectful debate.

The authors are very tentative here, and I think they rightly hesitate, for there is something strange about this proposal. Clearly, ethics is good at unearthing assumptions. In its academic form, it can clarify disagreements, in its consensus-seeking form it has been pointing the way to international law. Yet even consensus does not seem to be enough for sufficient action and we are told that ethics can also lead the way to a greater motivation. But what makes the authors think so? If motivation were a matter of ethics, should not the overwhelming urgency of the moral challenge, and Singer's powerful arguments, long have done the work? They haven't, and perhaps we should not be surprised, because motivation is not a mere matter of arguments; it involves our emotions, our intuitions, our deep-seated tendencies. It involves many things that in this book have been noted in passing, only to be left behind immediately: our tendency to prioritize the short term and the nearby, to conform to our environments, to have short attention spans, etcetera. Much work in these areas has been and is done by moral and social psychologists, as well as 
behavioral economists. A picture emerges from these disciplines of people as extremely sensitive to the characteristics of their situation. From this perspective, an important question becomes how we can nudge our poor situation-dependent selves into doing good, and institutionalized ethics might be far more helpful than the editors of this book seem to think. I suspect that concerning our lack of motivation, it is not ethics but these empirical disciplines that are going to be most helpful. At the very least, ethics should seek their assistance, as it has not done in this book.

One of the good things of globalization is the emergence of a global perspective. The inequalities that emerge in this perspective are ghastly, but they should be confronted and it is a hopeful development that ethics is increasingly doing so. The effort in this book to find out how ethics can help has yielded a rich collection of data, views, and insights, but does not fully convince in the kinds of help it offers. A more pragmatic message is hidden below the surface, which is the "all hands on deck" view that help is needed from empirical motivation disciplines.

Open Access This article is distributed under the terms of the Creative Commons Attribution Noncommercial License which permits any noncommercial use, distribution, and reproduction in any medium, provided the original author(s) and source are credited. 